\title{
Evaluating the Kindergarten Instructional Materials: Inputs for Materials Production
}

\author{
Ma. Rebecca A. Abayana, Majean B. Placigo ${ }^{b}$, Las Johansen B. Caluza ${ }^{*}$ \\ abayanmarebecca@gmail.com, ${ }^{b}$ majtinarosaroso@gmail.com, ${ }^{c}$ lasjohansencaluza@lnu.edu.ph \\ Leyte Normal University, Tacloban City 6500, Philippines
}

\begin{abstract}
Instructional materials are tools necessary in making the teaching-learning process effective and meaningful for the learners. They help enhance instruction thereby uplifting the students' knowledge, skills and abilities. However, teachers experience problems pertaining to lack of appropriate and rich resource of instructional materials, thereby limiting their capacity to provide meaningful learning opportunities. This is a qualitative research which aimed to find out the availability of teaching materials in the Kindergarten classes of a public elementary school. It is grounded on the experiential learning theory in using instructional materials through concrete experience. Employing the descriptive phenomenology design and utilizing the Colaizzi's descriptive phenomenological method of data analysis, it further tried to determine the challenges experienced by the teachers in the production of instructional materials. The purposive sampling technique was employed to select the participants, who are all Kindergarten teachers. The findings revealed that the Kindergarten classrooms lacked developmentally appropriate materials necessary for effective teaching and learning, and teachers were burdened in the production of teaching materials due to some factors. Results of this study may provide inputs in the production of instructional materials for Kindergarten.
\end{abstract}

Keywords: instructional materials, Kindergarten, evaluation, experiential learning theory, Colaizzi's descriptive phenomenological method

\section{Introduction}

The preschool education requires a stimulating environment that would bring about learning to its optimum level. To provide an effective simulative environment in the process of teaching and learning, many factors such as children's readiness, classroom environment, teaching methods, assessments, and teaching aids make an impact. Among different factors, teaching aids make a direct influence on both teaching and learning (Rajapaksha \& Chathurika, 2015).

Instructional materials play a significant role in the success of the teaching-learning process. For the teachers, instructional materials are important to aid the teacher for the effective delivery of the lessons. Abdullahi and Effiong (2015) contend that instructional materials are tools locally made or imported that help to facilitate the teaching/learning process. Isola (2010) referred the instructional materials as objects or devices that aid the teacher to make a lesson much clearer to the learners.

Phyllis on Onditi (2018) stipulates of some innate advantages of instructional materials to the teaching and learning. In terms of instruction, teachers are provided with compelling platforms for conveying information because they raise the level of interest to learn. Moreover, they provide opportunities for private study and reference, that stimulate the learner's interest and curiosity towards learning. Furthermore, the use of instructional materials helps the teacher to present difficult concepts with ease. Generally, they make teaching and learning easier and less stressful. They are equally indispensable catalysts of social and intellectual development of the learners.

It is the prime responsibility of the teachers to deliver the lesson effectively to the students. And, it is a common goal for them to ensure that the presentation of the lesson is stimulating, engaging, and motivating for the learners. To reach this goal, teachers need to employ varied and suitable instructional materials that would help meet the individual needs of the learners. For learning to take effect, it is very important also to give consideration on the selection, production and effective use of these materials by the teachers. Wambui (2013) stated Piaget's theory that "merely using instructional materials does not guarantee effective teaching, to make teaching and participation effective, the instructional materials must be appropriately selected and used." The teacher then uses these materials to deliver the lesson effectively following the teaching methodologies and strategies that the teacher has in mind.

Effective use of instructional materials in teaching helps raise the level of interest of the students toward the lesson. Agina-Obu (2005) describes instructional materials as concrete or physical objects, which provide sound, visual or 
both to the sense organs during teaching. This makes learning more meaningful, and the presentation of the concepts becomes more appealing and interesting for the students. Savoury as mentioned by Onditi (2018) contends that a carefullyplanned use of instructional materials in lessons should do much to take away boredom and dullness in presenting the lesson. He added that apart from ensuring that learners achieve an in-depth understanding of the lesson, such materials should make the lesson attractive to the learners, thereby drawing their attention and thus, motivating them to learn and participate.

Instructional materials play various roles in the teaching-learning process. Brown (2000) summarized the role of teaching aids as follows:

- "They promote meaningful communication and effective learning.

- They ensure better retention, thereby making learning more permanent.

- They help to overcome the limited classroom by making the inaccessible accessible.

- They provide a common experience upon which late learning can be developed.

- They stimulate and motivate students to learn.

- They encourage participation especially if students can manipulate materials used."

In the preschool curriculum, the use of instructional materials is indispensable. It draws a huge weight for effective teaching and learning. Teaching basic concepts rely heavily on the use of instructional materials, which make the concepts and ideas more concrete, easy to remember, and more understandable for the young learners. Hence, the preschool classroom is expected to be an environment that provides a rich source of learning opportunities through the different materials and instructional aids made available by the teacher. Instructional materials boost teaching and learning as they stimulate thinking and concretize learning (Ige, 2000).

The environment plays a critical role in providing a rich learning experience for the learners. The richer the environment, the more concrete opportunities there are for learners to learn by interacting with instructional materials. The teacher's role is to create an environment that invites learners to observe, to be active, make choices and to experiment. Instructional materials are tools used for teaching and learning, which support the teacher in the delivery of knowledge or helps emphasize specific knowledge. According to Thungu (2008), instructional materials meet the needs of learners, fulfill the requirements of the subjects and facilitate the teaching and learning process.

In terms of providing a rich appropriate environment for pre-schoolers, the National Association for the Education of Young Children (NAEYC) sets some guidelines in terms of developmentally appropriate practices in the selection of materials for children: appropriate to the child, appropriate to the group, and appropriate to the culture. The essential aspects of the preschool environment are the presence of the different learning centers, which aim to develop and enhance basic skills and competencies suitable for their level. Such characteristics are expected to be observable in a preschool classroom to ensure that effective teaching and learning is achieved.

Kindergarten classrooms need to be equipped with developmentally appropriate materials. Toys and materials should be culturally relevant, developmentally appropriate, linked to children's interests, varied toys and activities, and linked to learning goals. Moreover, preschool learning environments have to cater towards creation of common interest areas (Dodge et al., 2010), which are recommended as key tools in learning, namely: blocks, toys and games, art, library, discovery, sand and water, music and movement, cooking and computers.

The teachers' daily concern does not simply call for one's ability to make lesson plans and deliver them well to the class. One important responsibility of the teacher is to provide appropriate and suitable instructional materials that could help aid the teacher in ensuring that the lesson will bring about expected outcomes. One way of doing so it by means of producing appropriate and suitable materials for teaching.

However, studies reveal that many preschool classrooms are unable to provide the necessary materials and instructional aids that would lead to effective teaching. More and more teachers are faced with the problem of having very limited teaching resources in their classrooms.

In the local setting, many classrooms are experiencing lack of instructional materials. A great number of classrooms are not well-equipped with the necessary teaching tools, facilities and equipment to make learning more effective. In some public schools, for instance, teachers complain about the lack of appropriate materials for teaching. In addition to that, due to limited resources, teachers are forced to use inappropriate teaching materials for their lessons. The lack of support and training on the production and effective use of instructional materials for teaching becomes a draw back for the teachers. This somehow affects the performance of teachers and students.

There are few studies in the local setting that describe the available instructional materials in the kindergarten classrooms and the problems encountered by teachers in the use of such materials. Moreover, there are very few studies that clearly aimed at identifying what particular kinds of instructional materials are needed in the kindergarten classroom that suits the needs of the teachers in the public school setting. It is on this premise that this study is conducted. This study aims to find out the availability of instructional materials in the kindergarten classrooms of a public school in Tacloban City Division. 


\section{Research questions:}

Specifically, this study seeks to answer the following questions:

1. What instructional materials are available in the kindergarten classroom?

2. What other kind of instructional materials are needed in the Kindergarten classroom?

3. What challenges do the teachers experience in terms of the use of instructional materials in the classroom?

\section{Theoretical framework}

This study drew some theoretical underpinning from the Experiential Learning Theory propounded by Kolb (1984). He proposed a four-stage learning process with a model that is often referred to in describing experiential learning. The process can begin at any of the stages and is continuous, that is, there is no limit to the number of cycles you can make in a learning situation. This theory stipulates that learners learn using instructional materials in steps with the likelihood of developing one mode of learning more than another. The characteristics of this theory are through concrete experience, observation and reflection, abstract conceptualization, and active experimentation.

Many kindergarten materials would allow for the direct experience that it could offer to the learners. For instance, the use of realia or real objects in teaching makes learning more meaningful, lasting and authentic. Actual exposure to such kinds of teaching aids promotes effective learning.

This theory directly relates to the study in the sense that as the teachers employ different instructional materials in teaching, students interact with such materials in various activities prepared by the teacher. The purpose of such materials is to concretize the abstract ideas presented in the lessons, and to make the ideas and concepts vivid to the learners. As the learners interact with the materials, the learners directly associate themselves to the materials, draw from their background knowledge, and connect them to the material.

In the kindergarten level, the use of such instructional materials is so crucial that learners depend much on the said materials in the formation of basic ideas about the things around him. Hence, the teachers in the preschool classroom need to ensure that they use appropriate and suitable materials that will enhance learning on the part of the learners.

\section{Methodology}

\subsection{Research design}

This is a qualitative research study employing the descriptive phenomenology design. Descriptive phenomenology is widely used in social science research as a method to explore and describe the lived experience of individuals (Christensen, Wekch, \& Barr, 2017). It specifically focuses in describing the lived experiences of the participants on the availability of kindergarten materials in the classrooms, other needed materials, and the challenges experienced by the kindergarten teachers.

\subsection{Participants}

All the kindergarten teachers from the target public elementary school were selected through purposive sampling technique to draw out pertinent information about the study. They have been handling the kindergarten classes for several years already.

\subsection{Instruments of the study}

The researchers used several instruments for data collection namely; survey questionnaire, interview guide, and check lists to draw pertinent data relative to the study. These instruments were examined or checked and pre-tested in the pre-school classroom of a different institution. It has likewise undergone the scrutiny of research experts particularly on the area of instructional materials.

\subsection{Data collection}

The researchers sought permission by sending letters to the principals or heads of the school regarding the conduct of the study. The teachers were personally informed by their school heads regarding their participation in the study. In the actual conduct of the interview, the researchers first described the nature and purpose of the research study. A focusedgroup-discussion (FGD) was administered to the three kindergarten teachers. The researchers were guided by the interview guide in terms of asking the right questions to the participants. Permission was sought in recording the conversations to ensure that the interview will be properly documented. After the interview, a short tour around the different classrooms was done, and pictures were taken to document the different kinds of materials and instructional aids and teaching materials that 
are available in the classroom.

\subsection{Reflexivity}

The researcher tried to ensure that only the ideas of the participants were the focus of the study and that their experiences as well as the actual utilization of the materials were reflected in the results.

\subsection{Data analysis}

After gathering the data, the researchers analyzed the transcriptions based on the statements given by the participants in the recorded interview and focus group discussion. The researchers read the transcriptions several times in order to generate the codes. Colaizzi's (1978) distinctive seven step process provides a rigorous analysis, with each step staying close to the data. The end result is a concise yet all-encompassing description of the phenomenon under study, validated by the participants that created it (Morrow, Rodriguez, \& King, 2015). The stages are illustrated in the table below:

Table 1. Steps in Colaizzi's descriptive phenomenological method

\begin{tabular}{|ll|l|}
\hline Step & Description \\
\hline $\begin{array}{l}\text { 1. } \\
\text { Familiarization of the } \\
\text { data }\end{array}$ & $\begin{array}{l}\text { The researchers familiarizes him or herself with the data, by reading } \\
\text { through all the participant accounts several times. }\end{array}$ \\
\hline 2. & $\begin{array}{l}\text { Identifying significant } \\
\text { statements }\end{array}$ & $\begin{array}{l}\text { The researchers identifies all statements in the accounts that are of } \\
\text { direct relevance to the phenomenon under investigation. }\end{array}$ \\
\hline 3. & Formulating meanings & $\begin{array}{l}\text { The researchers identifies meanings relevant to the phenomenon that } \\
\text { arise from a careful consideration of the significant statements }\end{array}$ \\
\hline 4. & Clustering themes & $\begin{array}{l}\text { The researchers clusters the identified meanings into themes that are } \\
\text { common across all accounts. }\end{array}$ \\
\hline 5. & $\begin{array}{l}\text { Developing an } \\
\text { exhaustive description }\end{array}$ & $\begin{array}{l}\text { The researchers writes a full and inclusive description of the } \\
\text { phenomenon, incorporating all the themes produced at step 4. }\end{array}$ \\
\hline 6. & $\begin{array}{l}\text { Producing the } \\
\text { fundamental structure }\end{array}$ & $\begin{array}{l}\text { The researchers condenses the exhaustive description down to a short, } \\
\text { dense statement that captures just those aspects deemed to be essential } \\
\text { to the structure of the phenomenon. }\end{array}$ \\
\hline 7. & $\begin{array}{l}\text { Seeking verification } \\
\text { of the fundamental } \\
\text { structure }\end{array}$ & $\begin{array}{l}\text { The researchers returns the fundamental structure statement to all } \\
\text { participants (or sometimes a subsample in larger studies) to ask } \\
\text { whether it captures their experience. He or she may go back and } \\
\text { modify earlier steps in the analysis in the light of this feedback. }\end{array}$ \\
\hline
\end{tabular}

\subsection{Ethical consideration}

The researchers followed the appropriate guidelines for issues such as human rights, and compliance with the law conflict of interest, safety, and health standard and others. They sought permission by securing permission from the Schools Division Superintendent and by sending letters to the school heads regarding the conduct of the study. The teacherparticipants were informed verbally in advance by their respective heads about their participation in the conduct of the study. The transcriptions in the recorded interviews were shown to the participants to ensure that the content of the transcriptions was correct. The researchers acknowledged all the authors used in any of this study and the participants were aware that their answers and individuality would remain confidential.

\section{8 Research locale}

This study was conducted in one of the public elementary schools in Tacloban City, Philippines, which offers preschool and elementary courses, with four classes in the Kindergarten levels. All classes in the preschool level were included to ensure that the data would provide the valid, reliable and accurate details about the status of available materials in the aforementioned classes.

\section{Results and discussions}

\subsection{Available materials in the kindergarten classroom}

\section{Printed materials}


The most common and most often used materials are the pictures. Pictures are the most commonly used and easy to prepare materials. Teachers in the field create a compilation of cut-out and well mounted pictures that are made available for use in teaching various subject areas. The said materials are often used and accessed by the teachers since most of the concepts taught by the teachers in the preschool classroom needed picture presentations. They are grouped according to kind and are kept in individual envelopes for easy storage and retrieval. Teacher immediate resort when videos and multimedia are unavailable is to use pictures to concretize the teaching of concepts in class.

They likewise keep a number of charts to aid them in teaching. Such charts are oftentimes those that are commercially distributed and sold in bookstores. They are often utilized by the teachers for wall decorations and bulletin board displays. Aside of their colorful and artistic presentations, charts effectively present the concepts with less burden on the part of the teachers.

Big books are reading materials with big colorful pictures and prints. They are often used in story reading activities, where the parts of the story are illustrated in big pictures. In the Kindergarten classroom, the most common materials are those ready-made or commercially-made big books.

\section{Manipulatives}

Manipulatives are materials that students manipulate in the teaching and development of concepts in the classroom. In the Kindergarten classroom, manipulatives are necessary in developing concepts relative to counting, sound production, textures, and the like. With the absence of commercially available materials, those available in their classrooms are improvised manipulatives collected by the teachers, such as marbles, soft drink cups, bottles, musical instruments, puppets, and others.

The Kindergarten classrooms have the following common instructional materials:

Printed Materials

- $\quad$ picture cut-outs

- charts

- $\quad$ ready-made big books

Manipulatives

- $\quad$ wooden blocks

- improvised materials for counting

- $\quad$ toys/play things

\subsection{Needed materials}

Results of the interview revealed of the essential teaching materials that teachers need in their classrooms.

\section{Multimedia materials}

The Kindergarten teachers saw the great need to use multimedia materials for an interesting way of presenting concepts in class. For the teachers, the use of multimedia materials enables students to learn best since many sense organs are utilized. Teaching of more difficult and abstract concepts become much easier when aided with such materials. For the Kindergarten teachers, the presence of projectors, speakers, or tv monitor in the classroom could enable them to present more effectively to their students. For the teachers, the use of such materials could increase the interest of the learners towards the lessons and would increase the students' capacity to learn.

\section{Manipulatives}

Kindergarten teachers also need the basic, appropriate and prescribed materials for Kindergarten classes in the development of concepts pertaining to develop numeracy skills, gross motor skills, language, vocabulary, and the like. They find them very necessary for effective teaching, especially that they had been taught and trained how to use such materials in the university where they graduated from. For the teachers, the absence of such materials affected their effectiveness as kindergarten teachers since they are fully aware of how necessary are those materials to their classes.

\section{Printed materials}

Big books are highly necessary for kindergarten classes. They are used in short story appreciation and vocabulary development. There may be available materials in the classrooms but they lack big books for Mother Tongue. The absence of such materials is clearly felt by the teachers, since they have no other materials to use for their storytelling and reading. They likewise need ready-made activity sheets, which could be provided to the students since the students do not have workbooks. Such activity sheets are necessary for practice exercises and mastery learning. 
In summary, these are the needed materials as follows:

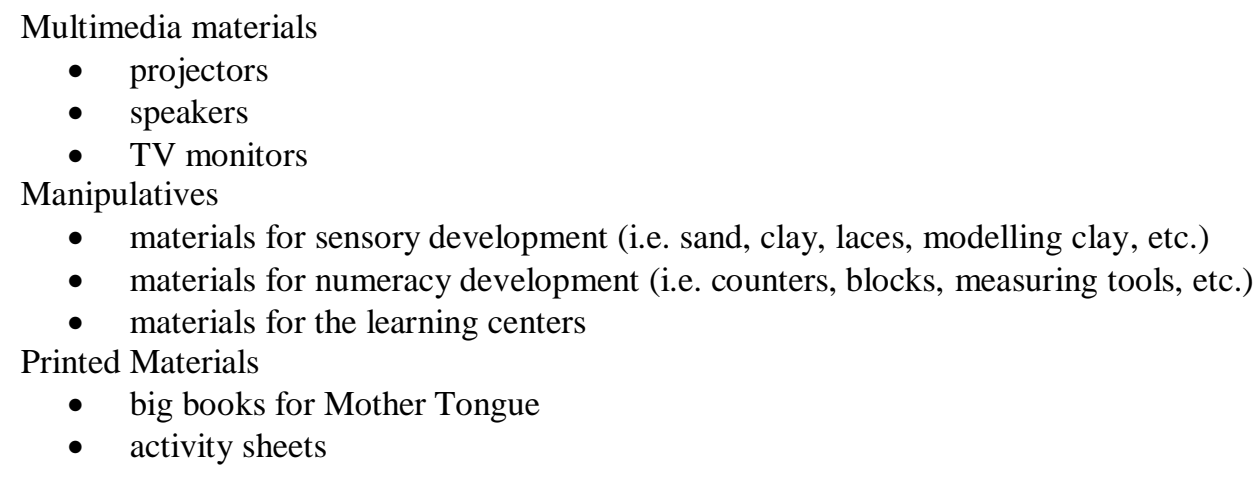

\subsection{Challenges faced by teachers in the production of materials}

Preparation of instructional materials may become challenging for Kindergarten teachers. The absence or lack of instructional materials may incapacitate teachers in delivering lessons effectively and systematically. Absence or lack of teaching materials is a common observation in many kindergarten schools. While buying such materials may be possible, teachers could still resort to producing their own materials in order to fit the kind and purpose for which they will be used.

The following identified factors were said to hinder them in the producing various teaching materials for instruction. These serve as challenges for the teachers: financial burden, production incapacity, time constraints, and additional workload.

\section{Financial burden}

A number of the teachers admit that making additional teaching materials will cause them to spend much money for the procurement of various materials. They only get a few materials from the school and from private institutions, but those materials that they feel are need are oftentimes provided by them. And since they handle all the subjects, it entails bigger expenses. Parents likewise do not contribute much for the production of teaching materials, especially that there is a "No Collection Policy" in school. In addition to that, they only get very limited materials from the school.

"It really costly on our part to be making such materials." (R1, p.3, line 15)

"Sometimes we ask support from parents, but we understand that parents are not

financially abled." (R2,page 3, lines 19-20)

\section{Production incapacity}

The skills to make such appropriate, effective and well-made instructional materials such as the big books seem to be a difficulty for most of them. The presence of such materials is very much necessary for Kindergarten classes in developing language and vocabulary of the pupils. However, according to them, they lack the necessary knowledge and skills to make their own big books. They lack training in terms of the technicalities and guidelines in making big books. Another difficulty for them is their lack of proficiency in the Waray language. They lack confidence to make such materials since, they themselves are not confident with the appropriate terms to use to suit to the Mother Tongue language.

line 24)

"We are asked to make big books in Waray waray mother longue, but it is very difficult for us." (R1, page 3,

"We are not so knowledgeable and confident in that language (Waray-waray) yet." (R1, page, line 26)

\section{Time constraints}

Production of materials become difficult on the part of the Kindergarten teachers. Since teachers are pre-occupied teaching all subjects the whole day with morning and after groups of students, they seem to lack time to prepare for different materials for every subject. According to them, it is very demanding in terms of time to be spent for the production of materials alone. They spend so much time in doing paper works after holding classes for the whole day session, and they lack enough time to plan and prepare materials for all lesson to be taught the following day.

"It is okay for us make such materials, however, it really takes a lot of time and money to produce them." (R. 2, 


\section{Additional workload}

Making instructional materials for specific lessons to be taught in class is an additional workload for them. From the preparation of individual plans for all the subjects, the Kindergarten teachers are likewise burdened checking all the task sheets for the different activities of the students in all subjects. With the absence of teacher assistants in the classroom, preparing materials for the individual subject gives additional burden for them.

"It is difficult for us to make the materials because we have so many paper works to do." (R3, page 3, line 16)

In a capsule, the kindergarten classrooms are equipped mostly with teacher-made materials but lacked the developmentally appropriate materials suitable for the kindergarten class. Teachers are unable to produce materials, which are caused by financial burden, production incapacity, time constraints and additional workload.

\section{Conclusion and recommendation}

The Kindergarten classrooms are not fully equipped with developmentally appropriate materials specifically those that are very essential for the development of basic knowledge and skills in Kindergarten. Production of such materials proves to be a burden for the teachers due to lack of budget, capacity, and production skill. It is hereby recommended that schools will prioritize the procurement of essential kindergarten materials and equipment necessary for effective delivery of the lessons. School administration should likewise include faculty development seminars and trainings to equip their faculty with the knowledge and skills in the production of appropriate instructional materials that are necessary towards creating a high-quality classroom environment.

\section{Acknowledgements}

The researchers would like to thank Tacloban City Division for allowing them to conduct this study.

\section{References}

Agina-Obu, T. N. 2005. The relevance of instructional materials in teaching and learning in Robert-okah. I \& Uzoeshi, k. C. (Ed.). Theories practice of teaching, Port Harcourt: Harey Publication.

Brown, R. M. (2000). Curriculum and Teaching: An introduction to method of teaching. Ibadan:Macmillan Press.

Christensen, M., Welch, A., \& Barr, J. (2017). Husserlian Descriptive Phenomenology: A review of internationality, reduction and the natural attitude. Journal of Nursing Education and Practice, 7(8). 113. DIO: 10.5430/jnep.v7n8p113.

Colaizzi, P. (1978). Psychological research as a phenomenologist views it. In: Valle, R. S. \& King, M. (1978). Existential Phenomenological Alternatives for Psychology. Open University Press: New York.

Dodge, D. T., \& Kittredge, B. (2009). Room Arrangement as a Teaching Strategy DVD. Washington, DC: Teaching Strategies, Inc.

Effiong, O., Igiri, C. (2015). Impact of instructional materials in teaching and learning of Biology in senior secondary schools in Yakurr LG A. International Letters of Social and Humanistic Science, 62, pp. 27-33.

Herman, K., Welsh, K. Preschool materials guide. The South Carolina Department of Social Services. 2010.

Ige, N. P. (2004). Poor performance in Chemistry in Technical Colleges of education: Courses and Implications. Unpublished PGDE Project of Ahmadu Bello University, Zaria, Nigeria.

Isola, O.M. (2010). Effects of standardized and improvised instructional materials on students' academic achievements in secondary school physics. University of Ibadan, Ibadan.

Kolb, D.A. (1984). Experiential learning: Experience as the source of learning and development. Upper Saddle River, NJ: Prentice Hall.

McMillan, J. H. \& Forsyth, D. R. (2003). What theories of motivation say about why learners learn? In R. J. Menges and M.D. Svinicki. Teaching from Theory to Practice. New Directions for Teaching and Learning.

Morrow, R., Rodriguez, A. and King, N. (2015). Colaizzi's descriptive phenomenological method. The Psychologist, 28(8), 643-644 
Onditi, S.A. (2018). Effect of use of instructional materials on learner participation in Science classroom in preschool in Rongo Town. International Journal of Humanities and Social Science Invention, 7(9): 52-61.

Rajapaksha, R., Chathurika, R.D. (2015). Problems faced by preschool teachers when using teaching aids in the teaching learning process. Department of Early Childhood and Primary Education. The Open University of Sri Lanka. International Journal of Multidisciplinary Studies, 2(1): 97-109.

Robinson (J), Baker, M. (2016). The effects of Kolb's Experiential Learning Model on successful intelligence in secondary agriculture students. Journal of Agricultural Education, 57(3), 129-1444, doi:10.5032/jae.2016.03129

Stephen, U. S. (2015). Problems of improvising instructional materials for the teaching and learning of Physics in Akwa Ibom State Secondary Schools, Nigeria. British Journal of Education, 3(3): 27-35

VLS Professional Development. Pre-school Learning Environments. Retrieved from https://www.virtuallabschool.org/preschool/learning-environments/lesson-1

Wambui, S. E. (2013). Effect of use of instructional materials on learner participation in Science classroom in preschool in Kiine Zone Kirinyaga County Kenya. Department of Educational Communication and Technology, University of Nairobi. 